\title{
The genes road: impact of migration on newborn screening and health amid the COVID-19 pandemic in the Eastern Mediterranean region
}

\author{
Abdullahi Tunde Aborode ${ }^{1} \cdot$ Christos Tsagkaris $^{2} \cdot$ Ajagbe Abayomi Oyeyemi $^{3}$. \\ Onigbinde Oluwanisola Akanji ${ }^{3}$. Mohammad Yasir Essar ${ }^{4}$. Shoaib Ahmad ${ }^{5}$. \\ Uzzam Ahmed Khawaja ${ }^{6}$. Natália Cruz-Martins ${ }^{7,8,9}$ (D) $\cdot$ Gaber El-Saber Batiha ${ }^{10}$
}

Received: 25 March 2021 / Accepted: 2 August 2021 / Published online: 9 August 2021

(C) The Author(s), under exclusive licence to Springer-Verlag GmbH Germany, part of Springer Nature 2021

\begin{abstract}
Nearly two-thirds of migrants residing in camps in Europe are women and children. Many of these children, being born on the way without essential newborns screening, are at some point admitted to pediatric wards in asylum countries. With hospitals overwhelmed with COVID-19 cases, taking appropriate care of newborns becomes a considerable burden. In this frame, prevention, in the form of adequate newborn screening, emerges as a better and more feasible strategy than healing.
\end{abstract}

Keywords Migration $\cdot$ Newborn $\cdot$ Screening $\cdot$ Health $\cdot$ COVID-10 $\cdot$ Eastern Mediterranean region

\section{Editorial}

Migration has grown in numbers and diversity lately. The refugees and migrants' crisis has overwhelmed Europe, particularly in the Southern European Union (EU) member states, with refugees and refugee-like asylum seekers since 2015. Approximately 2.4 million refugees and refugee-like people and 860,000 asylum seekers were located in $27 \mathrm{EU}$ countries by the end of 2018. However, more than 160,000 migrants have been illegally reverted to their original countries every year (Hathaway 2010).

During the coronavirus disease 2019 (COVID-19) pandemic, about 900 irregular arrivals to the EU countries have been

Responsible Editor: Lotfi Aleya

Natália Cruz-Martins

ncmartins@med.up.pt

Gaber El-Saber Batiha

gaberbatiha@gmail.com

1 Healthy Africans Platform, Research and Development, Ibadan, Nigeria

2 Faculty of Medicine, University of Crete, Heraklion, Greece

3 Department of Anatomy, Nile University of Nigeria, Abuja, Nigeria

4 Medical Research Center, Kateb University, Kabul, Afghanistan

5 Punjab Medical College, Faisalabad, Punjab, Pakistan detected monthly despite the closure of entry points (Chamie 2020). Alarmingly, nearly two-thirds of the asylum seekers are women and children (The UN Refugee Agency 2016), and many of these children are born without essential newborns' screening and are at some point admitted to pediatric wards in asylum countries (Kroening et al. 2019). In addition, and with hospitals overwhelmed with COVID-19 cases, taking appropriate care of them becomes a huge burden. Thus, prevention is not only better but also more feasible than healing.

Few drops of blood are enough for bloodspot screening, and a test is carried out once the newborn leaves the hospital and 2 weeks after birth. For example, 31 congenital conditions,

6 Jinnah Medical and Dental College, Karachi, Pakistan

7 Faculty of Medicine, University of Porto, Alameda Prof. Hernani Monteiro, 4200-319 Porto, Portugal

8 Institute for Research and Innovation in Health (i3S), University of Porto, Rua Alfredo Allen, 4200-135 Porto, Portugal

9 Institute of Research and Advanced Training in Health Sciences and Technologies (CESPU), Rua Central de Gandra, 1317, 4585-116 Gandra, PRD, Portugal

10 Department of Pharmacology and Therapeutics, Faculty of Veterinary Medicine, Damanhour University,

Damanhour, AlBeheira 22511, Egypt 
including cystic fibrosis, congenital adrenal hyperplasia, hemoglobinopathies, Duchenne's muscular dystrophy, hypothyroidism, and metabolic disorders, like phenylketonuria, homocystinuria, galactosemia, and maple syrup urine disease, can be diagnosed using genetic testing. These conditions have in common that they are manageable if diagnosed early but can lead to lifelong impairment if left untreated (Moreno 2016).

On the other hand, the burden of mental and motor retardation complications is unbearable for anyone, let alone migrants with minimal or no health insurance and resources. Under normal circumstances, even tertiary pediatrics departments could provide no more than supportive care (Kotsiou et a., 2018). The experience from the second spike of the pandemic in Europe indicates that such departments reaching full capacity may not take in migrants' newborns with phenylketonuria or cretinism (Kotsiou et a., 2018). Similarly, newborns admitted to cystic fibrosis or intestinal exacerbations are at significant risk of being infected with SARS-CoV-2.

Recent studies have reported worse perinatal outcomes and higher mortality among infants in migrant populations settling in developed countries (Gissler et al. 2009). Both before and during the COVID-19 pandemic, newborn migrants are in a perilous position. Lack of resources, limited access to healthcare facilities, financial instability, language, and cultural barriers are part of their everyday life. Newborns with congenital conditions moving from country to country or settling in remote camps rarely have a proper medical record or a physician who knows their history.

It is reported that more than 529,000 women die every year due to complications from giving birth and neonatal diseases. However, the Eastern Mediterranean region contributes to onetenth of global maternal deaths with an approximation of 53,000 deaths rates every year (WHO Regional Office for the Eastern Mediterranean 2006). Moreover, Afghanistan and Pakistan shared $60 \%$ of the burden of maternal mortality in the Eastern Mediterranean region, and 95\% of the prevalence of neonatal diseases and maternal rates are shared between Afghanistan, Iraq, Morocco, Pakistan, Somalia, Sudan, and Yemen (WHO Regional Office for the Eastern Mediterranean 2006) (Table 1).

On top of these, they are more prone to accidents, injuries, and infections because of the circumstances they live (Kotsiou et al. 2018). Indeed, with the pandemic exposing these adversities, it is high time to consider solutions and to implement an action plan for newborns screening.

In this way, identification and communication are of the utmost importance. This means, for example, that if an infant is diagnosed with phenylketonuria in Turkey, its records need to be accessible in English to physicians in Greece or Italy, so that an appropriate diet is not discontinued. It is essential for children with rare congenital disorders, such as Krabbe disease, that the physician who diagnosed them in Libya can communicate with the physician treating them in Spain.
Table 1 Data on the demographic of infant mortality due to neonatal diseases in the immigrant population in the Eastern Mediterranean region (United Nations Children's Fund 2012)

\begin{tabular}{|c|c|c|c|}
\hline Country & $\begin{array}{l}\text { Infant mortality } \\
\text { due to neonatal } \\
\text { diseases (per } \\
\text { 1000) } 1990\end{array}$ & $\begin{array}{l}\text { Infant mortality } \\
\text { due to neonatal } \\
\text { diseases (per } \\
\text { 1000) } 2013\end{array}$ & $\begin{array}{l}\text { Drop-in } \\
\text { neonatal } \\
\text { mortality rates } \\
\text { (\%) 1990-2013 }\end{array}$ \\
\hline $\begin{array}{l}\text { Eastern } \\
\quad \text { Mediterran- } \\
\text { ean region }\end{array}$ & 33 & 21 & 36 \\
\hline Bahrain & 8 & 6 & 75 \\
\hline Lebanon & 16 & 5 & 68 \\
\hline Egypt & 33 & 12 & 64 \\
\hline Tunisia & 24 & 9 & 63 \\
\hline Oman & 18 & 7 & 63 \\
\hline Iran & 26 & 10 & 60 \\
\hline Libya & 21 & 9 & 59 \\
\hline Saudi Arabia & 21 & 9 & 58 \\
\hline Qatar & 10 & 4 & 57 \\
\hline Syria & 18 & 8 & 56 \\
\hline $\begin{array}{l}\text { United Arab } \\
\text { Emirates }\end{array}$ & 10 & 5 & 50 \\
\hline Kuwait & 9 & 5 & 48 \\
\hline Jordan & 19 & 11 & 41 \\
\hline Yemen & 42 & 26 & 38 \\
\hline Afghanistan & 50 & 36 & 28 \\
\hline Iraq & 26 & 19 & 28 \\
\hline Pakistan & 56 & 42 & 25 \\
\hline $\begin{array}{l}\text { State of } \\
\text { Palestine }\end{array}$ & 13 & 12 & 5 \\
\hline
\end{tabular}

In reality, an international patients' identification number could make this plan possible. Thus, proper collaboration and coordination between countries facing migration flows are required. However, the benefit of avoiding exacerbations and hospitalization can be comparable to the expenses in the long term.

In addition to this, newborns' screening should be adapted to the migrating populations' inherent traits. This means that all newborns should be tracked and screened as per protocols, given that many babies are born in camps or on the way are not in proper facilities (Liem et al. 2020). Moreover, a growing body of evidence suggests that particular diseases are more prevalent among specific nationalities. For example, a recent analysis has detected 166 inherited conditions in newborns of Syrian origins (Copenhagen: WHO Regional Office for Europe 2018; Hamad et al. 2020). Therefore, it would be wise to include the most prevalent and debilitating diseases in the newborns' screening protocols. Finally, yet significantly, patients' education always matters. In newborn screening, migrating parents need to be educated to seek medical attention for their newborns (Baumeister et al. 2019). 
The data on migration of the migrants in the Eastern Mediterranean region, according to the International Organization for Migration, reported that around $3123 \mathrm{mi}-$ grants and refugees go to Europe via different paths and seas (May 2020) which account for $88 \%$ more than the one noted in the past months and two times than last year (International Organization for Migration 2020). The social determinants of health of the migrants in the Eastern Mediterranean region include poverty, illiteracy, malnutrition, and low social status of women are all underlying causes of maternal and neonatal mortality. Neonate delivery is a significant determinant of neonatal and future child health. Results from low birth weight, congenital anomalies, other hereditary diseases (blood diseases, etc.), and other social factors, like poverty, illiteracy, and many more, might be an indirect cause of death or a source of weak health and disability in the future (Wikkeling-Scott et al. 2019).

The high prevalence of low birth weight $(19.5 \%)$ in the region is a matter of concern. Low-birth-weight infants are at 40 times greater risk of neonatal death than normal-weight babies and are 5 times greater risk of postneonatal deaths. However, low-birth-weight babies constitute $19.5 \%$ of children born; they account for $60-80 \%$ of neonatal deaths either directly or indirectly (WHO Regional Office for the Eastern Mediterranean 2006; Lawn et al. 2005; Darmstadt 2005). In fact, considering the vast number of women who may give birth while relocating and the language barrier, translators and social workers can be advised to convey relevant information (Kotsiou et al. 2018) (Fig. 1).
Despite the need for enhancing health literacy among migrants has already been recognized, multiple interventions to tackle it have been studied (Baumeister et al. 2019) but other ways should also be better exploited. Anyway, in a time when healthcare facilities struggle with the pandemic and the migration crisis, early diagnosis and management are pivotal. Thus, the road of genes can follow wild patterns of exacerbation from Africa or Asia to Europe to the Eastern Mediterranean region. However, international and interdisciplinary collaboration is necessary to reach a permanent solution to this problem.

Author contribution Methodology: A.T.A., C.T., A.A.O.; literature search: A.T.A., C.T., A.A.O., O.O.A., M.Y.E., S.A., U.A.K.; validation: N.C.-M., G.E.-S.B.; supervision: G.E.-S.B.; writing - original draft: A.T.A., C.T., A.A.O.; writing - review and editing: N.C.-M., G.E.-S.B.

Funding This research did not receive any specific grant from funding agencies in the public, commercial, or not-for-profit sectors.

Data Availability Not applicable

\section{Declarations}

Ethics approval and consent to participate Not applicable

Consent for publication Not applicable

Competing interests The authors declare no competing interests.

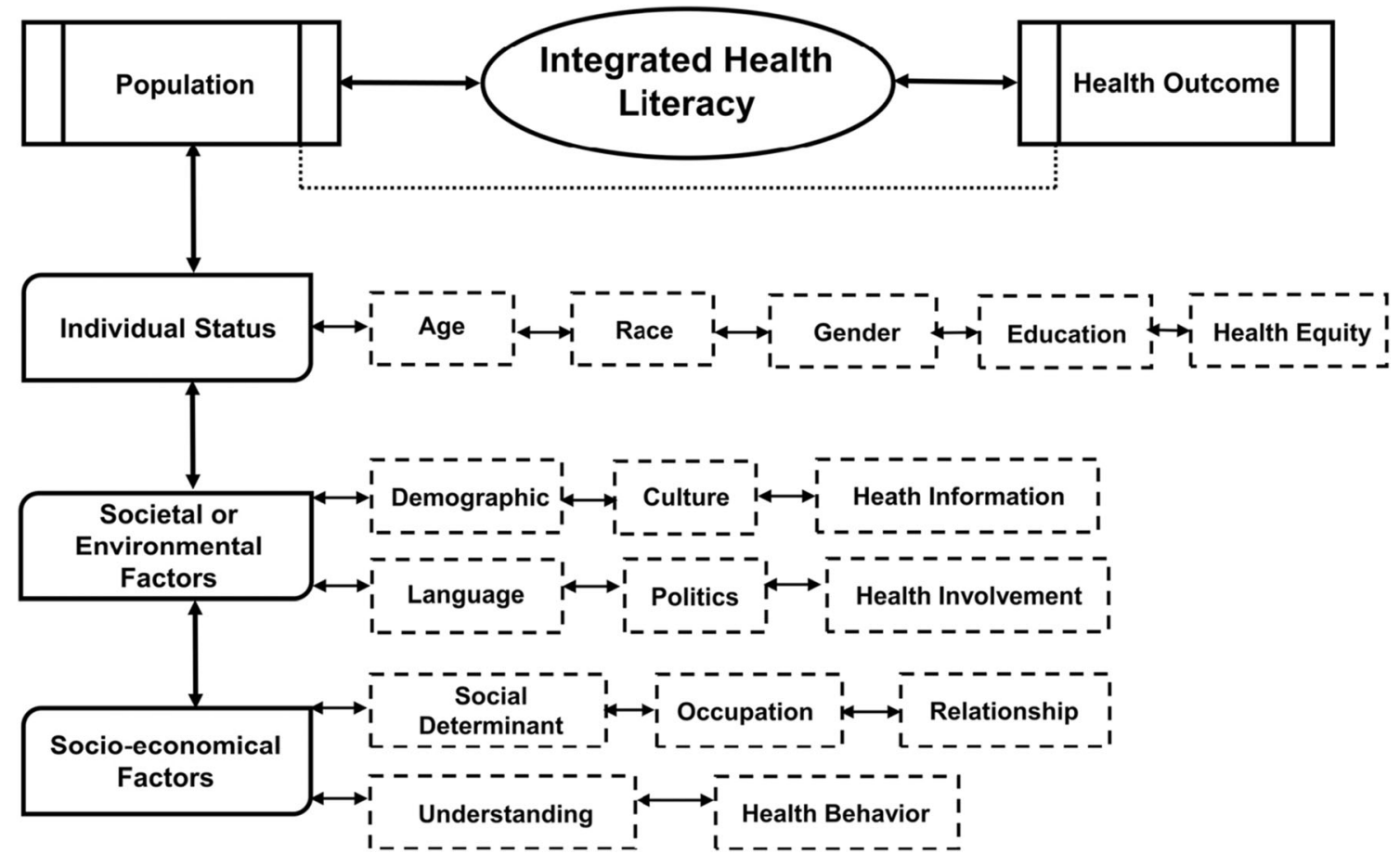

Fig. 1 Model of integrated health literacy 


\section{References}

Baumeister A, Aldin A, Chakraverty D, Monsef I, Jakob T, Seven ÜS, Anapa G, Kalbe E, Skoetz N, Woopen C (2019) Interventions for improving health literacy in migrants. Cochrane Database Syst Rev 4:13303. https://doi.org/10.1002/14651858.CD013303

Chamie J (2020) International migration amid a world in crisis. J Migr Hum Secur 8:3230-3245. https://doi.org/10.1177/ 2331502420948796

Copenhagen: WHO Regional Office for Europe; technical guidance on refugee and migrant health. 2018 (https://bit.ly/2KBY2qE, accessed on November 24 2020)

Darmstadt GL (2005) Evidence-based, cost-effective interventions: how many newborn babies can we save? Lancet Neonatal Survival Steering Team. Lancet 365:977-988

Gissler M, Alexander S, Macfarlane A, Small R, Stray-Pedersen B, Zeitlin J, Zimbeck M, Gagnon A (2009) Stillbirths and infant deaths among migrants in industrialized countries. Acta Obstet Gynecol Scand 88:134-148. https://doi.org/10.1080/00016340802603805

Hamad L, Kreidieh K, Hamdan MB, Nakouzi G, Yazbek S (2020) Mapping the diverse genetic disorders and rare diseases among the Syrian population: implications on refugee health and health services in host countries. J Immigr Minor Health 22:1347-1367. https://doi.org/10.1007/s10903-020-00987-7

Hathaway JC (2010) The global cop-out on refugees. Int J Refug Law 30: $4591-4604$

International Organization for Migration, 2020. Mediterranean migrants arrivals reach 16,724 in 2020; deaths reach 256. Available at: https:// www.iom.int/news/mediterranean-migrant-arrivals-reach-167242020-deaths-reach-256.

Kotsiou OS, Kotsios P, Srivastava DS, Kotsios V, Gourgoulianis KI, Exadaktylos AK (2018) Impact of the refugee crisis on the Greek healthcare system: a long road to Ithaca. Int J Environ Res Public Health 15:81790. https://doi.org/10.3390/ijerph15081790

Kroening A, Abigail LH, Dawson-Hahn E (2019) Health considerations for immigrant and refugee children. Adv Pediatr 66:87-110. https:// doi.org/10.1016/j.yapd.2019.04.003

Lawn, JE, Cousens S, Zupan J, Lancet Neonatal Survival Steering Team (2005) 4 million neonatal deaths: when? Where? Why?. Lancet 365(9462):891-900. https://doi.org/10.1016/S0140-6736(05) 71048-5

Liem A, Wang C, Wariyanti Y, Latkin CA, Hall BJ (2020) The neglected health of international migration workers in the COVID-19 epidemic. Lancet Psychiatry 7(4):20

Moreno MA (2016) Newborn Screening. JAMA Pediatr 170:6628. https://doi.org/10.1001/jamapediatrics.2015.2519

The UN Refugee Agency, Women refugees and asylum seekers in the European Union, 2016 (https://bit.ly/3pRRmF7, accessed on November 24 2020)

United Nations Children's Fund. Levels and trends in child mortality report Estimates developed by the UN inter-agency group for child mortality estimation. 2012, [updated 2012]. Available from: https:// www.unicef.org/media/files/2013_IGME_child_mortality_Report. pdf.

WHO Regional Office for the Eastern Mediterranean, 2006. Demographic and health indicators for the Eastern Mediterranean 2006. Cairo.

Wikkeling-Scott LF, Ajja RJY, Rikard RV (2019) Health literacy research in Eastern Mediterranean region: an integrative review. Int J Public Health 64(4):523-533. https://doi.org/10.1007/s00038018-01200-1

Publisher's note Springer Nature remains neutral with regard to jurisdictional claims in published maps and institutional affiliations. 